\title{
Method of resource saving of cable production recycables
}

\author{
Victoria Tsypkina ${ }^{1}$ and Daniyar Madrakhimov, ${ }^{2 *}$ \\ ${ }^{1}$ Tashkent State Technical University named after I. Karimov, Tashkent, Uzbekistan \\ ${ }^{2}$ Tashkent State Technical University named after I. Karimov, Tashkent, Uzbekistan
}

\begin{abstract}
The article discusses development of recycling technologies of cabling and wiring products with justification for the relevance of the cable waste use in the process as part of the closed technological cycle of cabling and wiring products manufacture. Sources of waste generation are analysed. Issues of uninterrupted operation and reliability of technological equipment, efficiency of the recycling process and problems of the development of processing technologies in cable production are highlighted.
\end{abstract}

Keywords: Material resources, cable production, cable waste, recycling, waste use, copper rod, polymer waste, closed process chain.

\section{Introduction}

Production of cabling and wiring products is a highly material-intensive process in which copper content in some groups reaches $90 \%$ (enameled wires). Therefore, reduction in the price of copper rod is a fundamental economic parameter, ensuring reduction in cost and increase of cable production competitiveness. Technological cycle, which includes production of copper rod from cable waste in comparison with production of copper rod from copper ore, determines high cost- efficiency of copper recycling, used in the process chain of cable production.

Organization of closed process chain of cabling and wiring products (CWP) is a priority for the development of any cable production, as it determines great economic benefit and high efficiency of all process and therefore development of cable waste processing (recycling) technologies is effective.

Closed process chain of production of cabling and wiring products includes all technological operations along the production route, from the production of wire rod (blanks, for electrical conductor) and ending with recycling of cable waste with its mandatory use in CWP production cycle.

Cable waste is a mandatory part of any technological operation and consists of entering ends (leaders) and rejected cable products, derived from the process cycle (table-1). Part of cable waste is recyclable products that can be used in technology with established percentage of the total raw material weight and materials, included in cable products design.
Table 1. Scrap of SWP cable, net mass $299.2 \mathrm{~kg}$.

\begin{tabular}{|c|l|c|c|}
\hline № & \multicolumn{1}{|c|}{ Components } & $\begin{array}{c}\text { Content, } \\
\mathbf{~ k g}\end{array}$ & $\begin{array}{c}\text { Content, } \\
\mathbf{\%}\end{array}$ \\
\hline 1 & Copper waste & 122,07 & 40,8 \\
\hline 2 & $\begin{array}{l}\text { Waste of insulating } \\
\text { polyethylene }\end{array}$ & 36,8 & 12,3 \\
\hline 3 & Waste of hose polyethylene & 84,67 & 28,3 \\
\hline 4 & Waste of plastic dye & 1,5 & 0,5 \\
\hline 5 & Aluminium foil waste & 22,74 & 7,6 \\
\hline 6 & Waste of tinned wire & 1,14 & 0,38 \\
\hline 7 & Waste of solder POS-40 & 0,04 & 0,01 \\
\hline 8 & PVC film waste & 23,33 & 7,8 \\
\hline 9 & PETF film waste & 2,39 & 0,8 \\
\hline 10 & Caprone thread waste & 0,48 & 0,16 \\
\hline 11 & Other waste (garbage) & 4,04 & 1,36 \\
\hline
\end{tabular}

Cable waste management process has evolved in the following stages [6]:

- waste burial, together with other wastes of industrial products and human life;

- burning to extract metal elements (First of all, copper);

- dismantling of cable structure elements;

- chopping and splitting into metal and non-metal parts;

- new ways to recycle cable waste [1].

Technological process of processing cable waste, used in practice, can be carried out by three methods [6]:

- Cable annealing on fire-this is the most primitive way, using which, polymer insulation is burnt simply to produce metal coated wires. This technology is the most harmful for both the environment and the processors themselves. In addition, a significant part of the surface layers that conduct wires, "goes" into scrap.

- Separating the cable from insulation manually, which is time-consuming and labour-intensive and recycles small volumes of cable.

\footnotetext{
* Corresponding author: daniyar_19@yahoo.com
} 
- Mechanical recycling of the cable on highperformance, specialized installation - such recycling consists of crushing the cable, after which the polymers and metals are separated in various ways, including electromagnetic way.

At that, the latter method is subdivided into methods that allow dividing and separating fragmented segments of cables and wiring into polymer and metal fractions, by electromagnetic separation, air vibro-separation or combined electromagnetic-air vibro-separation.

To date, in the production structure of cable companies in Uzbekistan only JV "Uzkabel" JSC (Tashkent) has a site for processing of cable waste (production of Switzerland) (Figure 1), which includes:

- $\quad$ sorting of cable waste;

- crushing into factions;

- separation;

- Recycling of waste in the production cycle;

- Waste disposal.

and refers to the combined method of electro-magnetic air vibro-separation.

Average performance of the applied technology at the inlet depends on the type of recycled cable and level of automation of auxiliary operations (table1).

Cable waste recycling line, designed for integrated cable waste recycling with the removal of magnetized fractions and obtaining copper and aluminum granulate, with simultaneous sorting and separation into fractions of electrical conductive metal (copper, aluminum), insulation material and ferrous scrap and waste [6].
Table 2. Average performance of the combined method of electro-magnetic air vibro-separation.

\begin{tabular}{|c|l|c|}
\hline № & Type of cabling and wiring products & $\begin{array}{c}\text { Average } \\
\text { performance, } \\
\text { kg/h }\end{array}$ \\
\hline 1 & for mixed copper cable & 700 \\
\hline 2 & for telephone wire & 650 \\
\hline 3 & for power cable & 1100 \\
\hline
\end{tabular}

Table 3. At the same time, purity degree of copper particles, obtained at the output, for different types of cables is on average.

\begin{tabular}{|c|l|c|}
\hline № & $\begin{array}{c}\text { Type of cabling and } \\
\text { wiring products }\end{array}$ & $\begin{array}{c}\text { Purity degree of copper } \\
\text { particles, obtained at the } \\
\text { output, \% }\end{array}$ \\
\hline 1 & for mixed copper cable & 99,5 \\
\hline 2 & for telephone wire & 99,8 \\
\hline 3 & for power cable & 99,9 \\
\hline
\end{tabular}

The principle of the line operation is to extract copper (aluminum) from the waste of cabling and wiring products (diameter from $0.1 \mathrm{~mm}$ or more) by crushing the raw materials into granules, and then extracting copper (aluminum) fractions from it. The line is a set of separate machines, connected by process chain through a system of air transport and belt conveyors, as well as a single system of air supply and purification (fig.1).

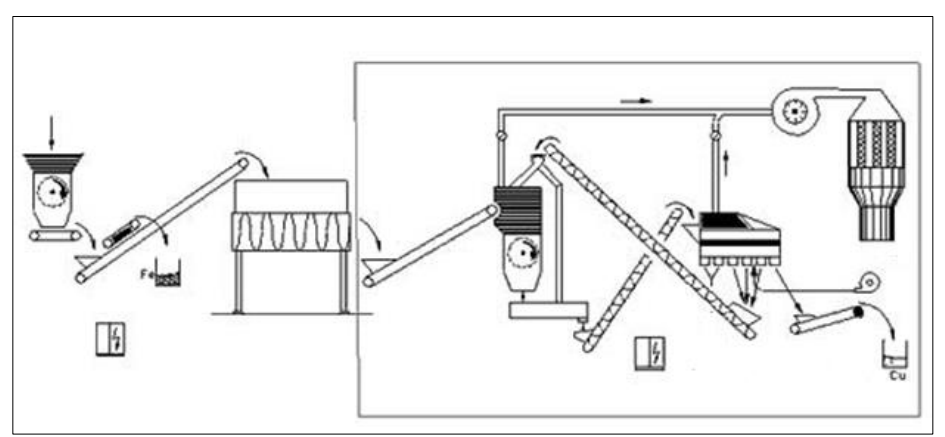

Fig. 1. Basic diagram of process line for recycling of cable waste

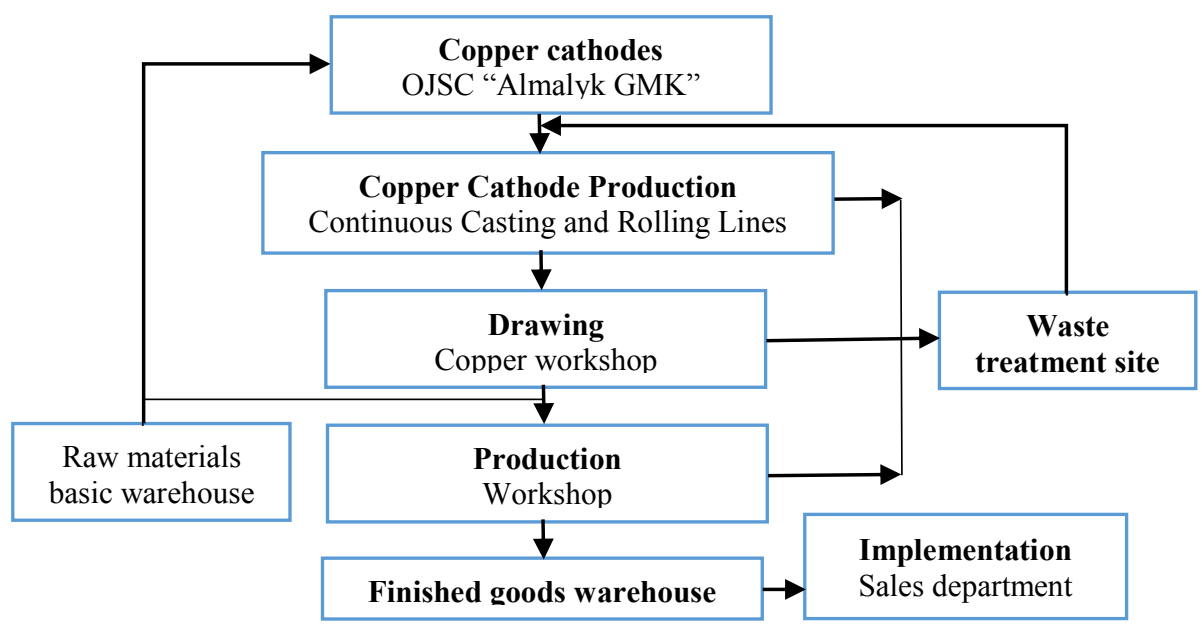

Fig. 2. Cabling and wiring products at "UZKABEL" JV JSC taking into account waste processing site 
Efficiency of the closed process cycle in the production of cabling and wiring products is in the amount of raw materials (copper and aluminum), used in the technology of obtaining copper and aluminum wire rod. Technological reworks of used raw materials look like this (pic. 2).

Technological cycles of producing copper wire rod from cathodes and waste of raw materials contain the same number of reworks, but energy consumption, labor and capital intensity of technologies are not comparable. Only consumption of electrical energy in the processing of copper waste into anode copper is 6 times less than in the processing of aluminum waste, which when compared with the cost of obtaining primary anode copper, starting from the mine, 20 times more [2].

Copper cable waste, received as a result of disposal, is fairly homogeneous, which is provided by modern purification technology, which is based on modern methods of recycling of recyclable materials waste.

Effectiveness of recycling is determined by economic indicators, and its assessment is obtained from formula $[3,7]$ :

$$
I_{e r}=F\left(E, E_{c} M\right) \rightarrow 1,0
$$

where $I_{e r}-$ Recycling Effectiveness Index; $E$ Recycling Effectiveness Index, showing cost ratio of products manufacturing from waste and from fresh raw materials (The cost of recycling waste should aim to minimum); $E_{c}$ - indicator of environmental importance of recycling, which reflects environmental harm, done by technology of producing product out of waste; ideally, recycling should not harm the environment; $M-$ indicator of relative volume of alleged recycling; ideally, $100 \%$ of waste should be recycled.

If these conditions are observed as much as possible, $I_{e r}$ tends to one. Indicator $I_{e r}$ speaks of the effectiveness of recycling for society as a whole, which in turn speaks on need for deep government involvement in the formulation of regulatory stimulating documents, related to the stages of waste formation, storage, recycling. This is necessary, in particular, due to the fact that for individual performers of works issues of ecology and depth of waste processing remain out of the sphere of attention [7].

In recycling of cable waste, environmental issues, completeness and depth of recycling are also relevant. However, for many cable manufacturers, financial efficiency comes to the fore, and the solution to the problem of obtaining recycled copper and aluminum comes down to a lighter way - burning off the waste of production.

The amount of cable waste is formed from production waste and time interval that corresponds to the amount of cables and wires consumption. Time interval is determined by the lifespan of the cable product (usually 25-30 years). However, lifespan depends on the operating conditions of cable products and can be up to one year, so for example, for oilsubmersible cables it is associated with a significant change in working conditions in geophysical wells.
Currently, Uzbekistan is experiencing a sharp increase in the consumption of imported electrical equipment and cable products. According to experts, in general, due to own production and copper receipts as part of imported cables and electrical products, copper consumption increased by about $20 \%$. This indicator should include cable products with expired service life 25 years, which need to be replaced. All this gives reason to expect an increase in copper waste inflow into recycling, which can reach $80 \%$, which will amount to 280.0 thousand tons of pure copper $[8,9,10]$.

However, in the process of cable waste recycling, there are problematic issues that need to be addressed by application of new technologies:

- recycling of thermoplastic polymer waste and its further use in production;

- Use of thermoreactive waste, as secondary raw material;

- Thermal treatment of polymers when burning rejected lengths and entering ends (leads) of cable products in compliance with sanitary standards and subsequent use of heat energy, released at the same time;

- deep separation of the polymer fraction, with the aim of increasing the percentage of secondary copper and aluminum;

- Increase in reliability of technological equipment operation, taking into account climatic features of the region (high air temperature in the summer).

- Process of using recycled copper and aluminum in the production of wire rod is conducting successive technological operations, starting with stripping cable waste, crushing with the separation of granular metal (armor and shell) and not metal (insulation and hose) fractions (chip scrap). Constraining factor in the use of heat plastic polymers waste for the production of copper and aluminum wire rod is the high dirtiness of waste with finely dispersed metal and non-metallic impurities and oil-containing fillers, technical complexity of removing them during recycling. For example, when recycling oil-submersible cables, copper is clogged with metal and non-metal materials, reservoir fluids.

Improvement of waste recycling technology should cover the process of cable waste generation. In this case, it is possible to use pre-selection of waste, prepare them for further processing, which will significantly reduce the clogging of waste by related materials. Such an organization will reduce labor intensity of waste recycling technology, eliminate clogging of copper and aluminum waste with excess impurities. Pre-selection technology is widely used in world practice in collection of plastic waste, in particular.

Various types of recycling technologies have been developed now that provide a comprehensive approach to recycling in cable industry and will remove all technical and organizational constraints.

Modern recycling technologies are presented in the market of technological equipment in the form of industrial plants, operation of which does not have a negative impact on the environment. However, effective process organization is possible only in large enterprises that specialize in collecting and recycling cable waste. 
These enterprises have sufficient financial, production and human resources to comprehensively address the existing problems in centralized waste collection, recycling and sale of produced commodity products with stable maintaining of required production volume and environmental frequency of the process, ensuring high quality of secondary product and low cost $[4,7,8]$.

Based on the analysis of existing recycling technologies, it can be noted that the development of recycling in cable production has a number of features:

- high social significance;

-Economically motivated for recycling plants and consumers of materials;

-modern recycling technologies are possible only with significant capital costs and are primarily available for large cable companies $[5,9,10]$.

With regard to the issue of material resources, natural resources are the determining factors. In recent decades, we can see exhaustion of some deposits, emergence of new deposits that is accompanied by a significant change in the geography of their location and, as a result, significant geopolitical upheavals. A negative global trend is the steady depletion of natural resources. Exploration of new deposits, conservation and efficient use of natural reserves is a vital task of the state.

\section{References}

1. G.I. Meschanov, Env.-ment. Asp. of CP, № 6 (2000)

2. O.P. Petrukov, The conc. of opt. int. man. of dom. Garb. in Moscow reg. / O.P. Petrukov, L.Ya. Shubov, F.F. Gaev // Dom. Garb., № 9 (2007)

3. G.I. Tsutskareva, Refl. on rec. waste, sci. and hi-tech., № 2, 56 (2015)

4. A.V. Sechina, Ov. of meth. of ind. Rec. of cab. waste // Writings of SSA, № 7, 80-89 (2009)

5. O.S. Kusrayeva, Form. man. mech. of wast. rec. of ind. Ent.: Auth. Abs. of Ph.D. thesis, 20 (St. Petersburg, 2012)

6. A.V. Sechina, Ov. of meth. of ind. Rec. of CW. https://docplayer.ru/33672417-Menedzhment-obzormetodov-promyshlennoy-pererabotki-othodovkabeley.html

7. A.V. Abramov, Asses. of rec. eff., MTUH, 36-38 (St. Petersburg, 2012)

8. B.B. Bobovich, V.V. Detkin Rec. of prod. and cons. waste. Int. Eng. (2000)

9. Yu.S. Yusfin, L.I. Leontiev, P.I. Chernousov. Ind. and the env. (2002)

10. Rec. of waste, №14 - 16 (2008) 